\title{
The role of proton magnetic resonance spectroscopy in the diagnosis and categorization of cerebral abscesses
}

\author{
Eftychia Z. Kapsalaki, M.D., ${ }^{1}$ Efstathios D. Gotsis, Ph.D., ${ }^{2}$ \\ and Kostas N. Fountas, M.D., Ph.D. ${ }^{3}$
}

${ }^{1}$ Departments of Radiology and ${ }^{3}$ Neurosurgery, University Hospital of Larissa, University of Thessaly, School of Medicine, Larissa, Greece; and ${ }^{2}$ Encephalos-Euromedica, Advanced Diagnostic and Research Institute, Athens, Greece

\begin{abstract}
$\checkmark$ Despite recent advances in neuroimaging, differentiation between cerebral abscesses and necrotic tumors with ringtype contrast enhancement can be puzzling at times. The introduction of advanced imaging techniques, such as diffusion-weighted imaging, has contributed to the identification of cerebral abscesses. However, differentiation may be impossible with imaging only. In this review the authors evaluate the role of proton magnetic resonance (MR) spectroscopy in differentiating between cerebral abscesses and necrotic tumors and address the spectral characteristics of intracranial abscesses. A large number of metabolites not detected in the normal brain spectra may be detected and give valuable information regarding the nature of the abscesses. Proton MR spectroscopy is a safe, noninvasive diagnostic modality, which could significantly increase the accuracy and specificity of conventional MR imaging in differentiating between malignant tumors and cerebral abscesses and provide valuable information regarding the cause of an abscess, as well as, its response to the chosen treatment. (DOI: 10.3171/FOC/2008/24/6/E7)
\end{abstract}

KEY WORDS $\bullet$ abscess $\bullet$ acetate $\bullet$ amino acid $\bullet$ lactate $\bullet$ lipid $\bullet$
proton magnetic resonance spectroscopy $\bullet$ succinate

I

T IS WELL KNOWN that abscesses represent $\sim 1-2 \%$ of all intracranial space-occupying lesions in the developed countries. ${ }^{13}$ This percentage rises to $8 \%$ in developing countries. ${ }^{13}$ Recently, there has been a well-documented increased incidence of intracranial abscesses in the developed world due to the exponentially increasing number of immunocompromised patients.

Although intracranial abscesses are still seen relatively infrequently-about 50 times less frequent than tumorsthe associated high rates of complications and mortality makes their prompt diagnosis crucial even in the current antibiotic era. ${ }^{47,49}$ The lack of any clinical signs in $~ 50 \%$ of patients with intracranial abscess, and the presence of nonspecific clinical signs or symptoms in the majority of symptomatic patients make the diagnosis difficult. ${ }^{16}$ In addition, other lesions such as malignant brain tumors of primary or metastatic origin that have similar space-occupying characteristics, but distinctly different management and prognostic implications, are not always easy to differentiate accurately and reliably before surgery. ${ }^{36}$ The neuroimaging techniques typically used (computed tomogra-

Abbreviations used in this paper: $\mathrm{ADC}=$ apparent diffusion coefficient; $\mathrm{DW}=$ diffusion-weighted; $\mathrm{MR}=$ magnetic resonance; $\mathrm{NAA}=\mathrm{N}$-acetyl-aspartate $\mathrm{PCr} / \mathrm{Cr}=$ phosphocreatine/creatine. phy and MR imaging) in a large number of cases cannot safely differentiate between an intracranial abscess, a cystic/necrotic glioma, a cystic/necrotic metastatic lesion, and a primary central nervous system lymphoma. ${ }^{19,21,28,33,35,50}$

Despite the introduction of newer MR techniques such as DW imaging, the problem of distinguishing cerebral abscesses from necrotic or cystic brain tumors remains unresolved. ${ }^{37}$ Although brain abscesses are associated with a high signal intensity on DW imaging and a reduced ADC value, while brain tumors usually manifest a low DW signal and high ADC value, there are reports of abscesses with low signal on DW imaging and high ADC values, or tumors with increased signal on DW imaging and low ADC values. ${ }^{31,37}$

This puzzling diagnostic dilemma could be less perplexing if the biochemical profile of these structurally confusing space-occupying lesions could be evaluated with noninvasive imaging techniques. Proton MR spectroscopy has been used to study the biochemical behavior of normal brain development, neonatal hypoxic-ischemic injury, inborn errors of metabolism, temporal lobe epilepsy, Alzheimer disease, demyelinating diseases, and intracranial tumors, and to differentiate between radiation necrosis and recurrent tumor with varying accuracy (Figs. 1 and 2). ${ }^{6}, 9,24,40,41,43,45,46,48,53,56$ Certain technical limitations to this noninvasive method, such as frequent contamination of the 


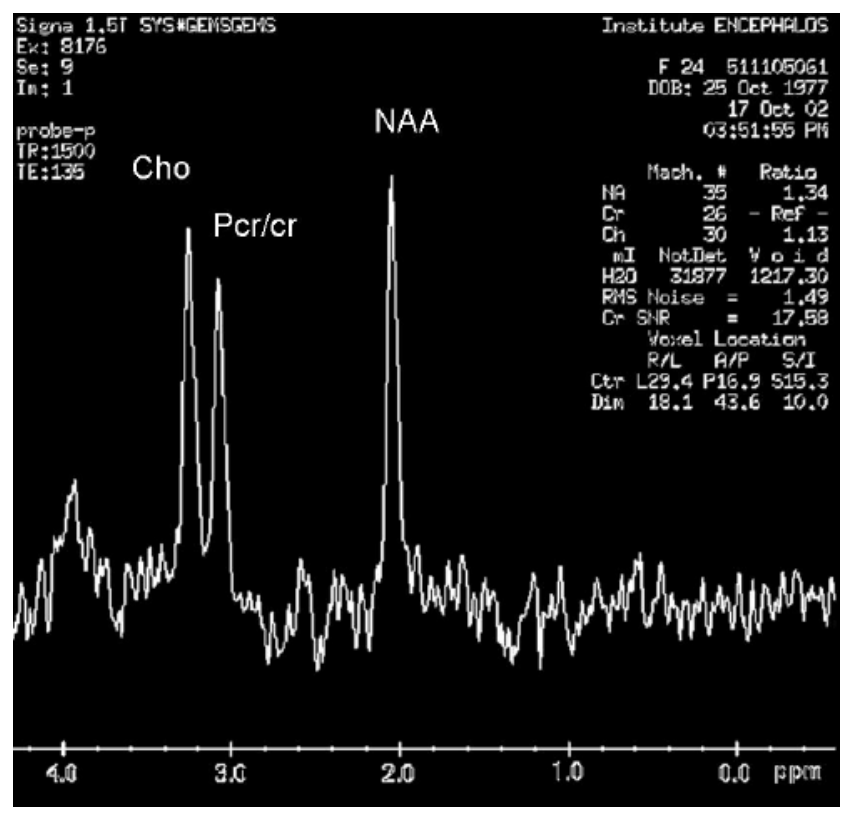

FIG. 1. Single voxel normal brain spectrum obtained with a 1.5-t MR unit (Signa HS, GE).

obtained spectrum, high signal-to-noise ratio, spectrum alteration caused by adjacent bone structures, and changing spectroscopic software packages, were responsible for the significant variations observed between the results of different clinical series. . $^{11,12,39}$ The improvement of the software and the accumulating experience with this methodology have transformed it into a useful and accurate noninvasive imaging modality with clinical applications, not only into brain tumor analysis, but also in studying a wide range of pathological intracranial conditions..$^{11,12,24,46}$
In the present study, we review the literature on the role of proton MR spectroscopy in the preoperative evaluation of space-occupying, ring-enhancing lesions and present the features characterizing the spectroscopic profile of intracranial abscesses.

\section{Literature Review}

\section{Technical Limiting Factors}

The clinical use of proton MR spectroscopy has increased exponentially with the improvement of spectroscopy software packages and increased understanding of the technical limitations and pitfalls of this noninvasive diagnostic modality. $6,11,12,24,40,41,43,45,46,48,53,56$ The early observations of wide variations in the efficacy of this modality in its clinical application in series of intracranial tumors, cerebral infarctions, or demyelinating lesions has been replaced with results characterized by high accuracy and reproducibility. $6,11,24,40,43,45,46,48,53,56$ The avoidance of signal contamination by appropriate localization of the studied voxel is of paramount importance for accurate spectroscopic analysis. It is widely accepted that even the slightest malposition of the voxel (a 1-cm voxel shift) results in 50\% signal contamination of the obtained spectrum from a hypothetical spherical lesion with $2-\mathrm{cm}$ diameter. It should be emphasized that particularly in suspected abscesses, the voxel must be appropriately placed at the center of the studied lesion. ${ }^{2,27}$ In addition, exclusion of calcifications, necrotic areas, and adjacent bone structures from the voxel are key elements in obtaining an accurate proton MR spectroscopy spectrum. ${ }^{11}$ Despite all the advances provided by the available spectroscopy software, this method requires the patient's cooperation and an experienced spectroscopist for obtaining and interpreting the raw data. ${ }^{39,54}$

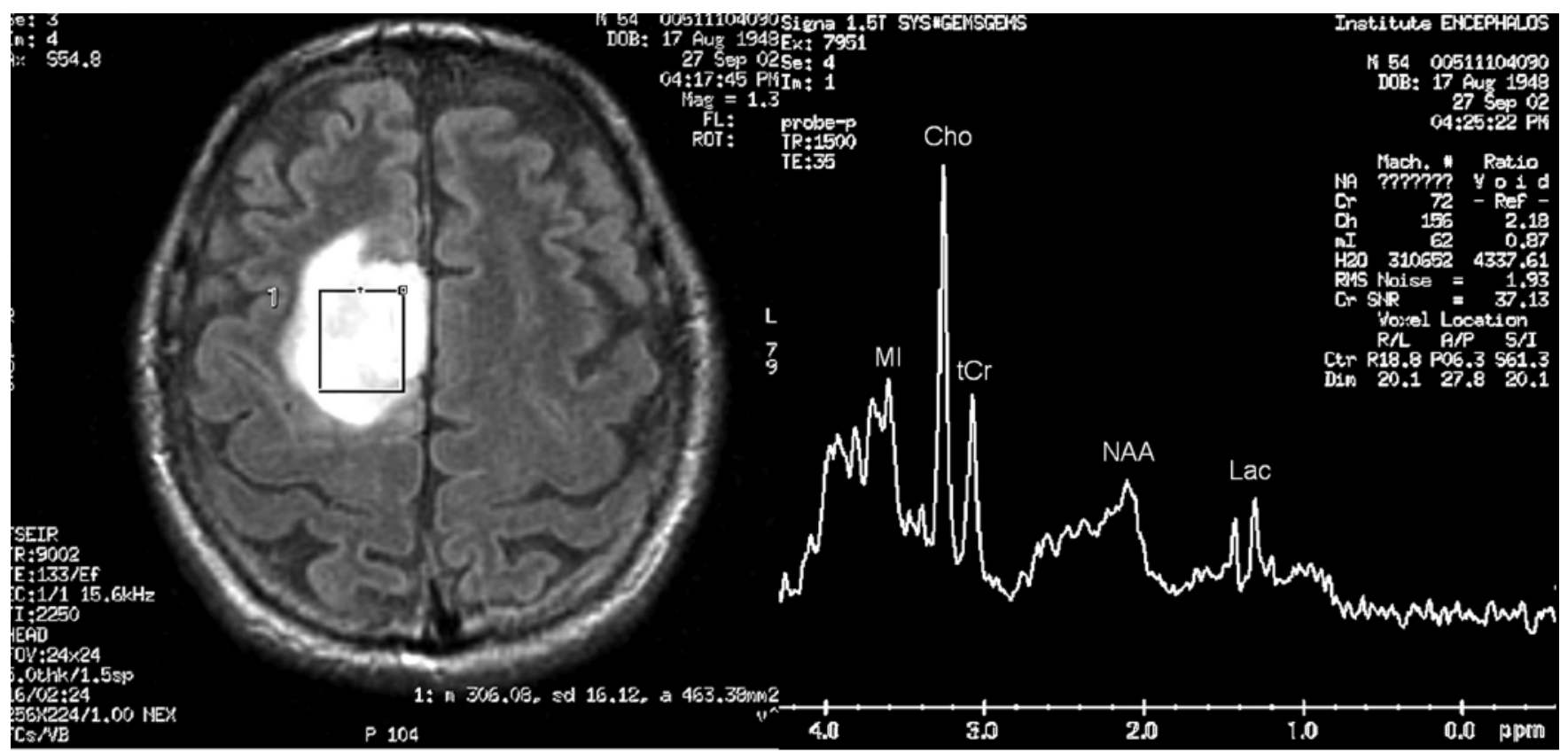

FIG. 2. Single voxel spectrum of a high-grade glioma obtained using a 1.5-t MR unit (Signa HS, GE) demonstrating total absence of NAA and an increased Cho/PCr ratio. 

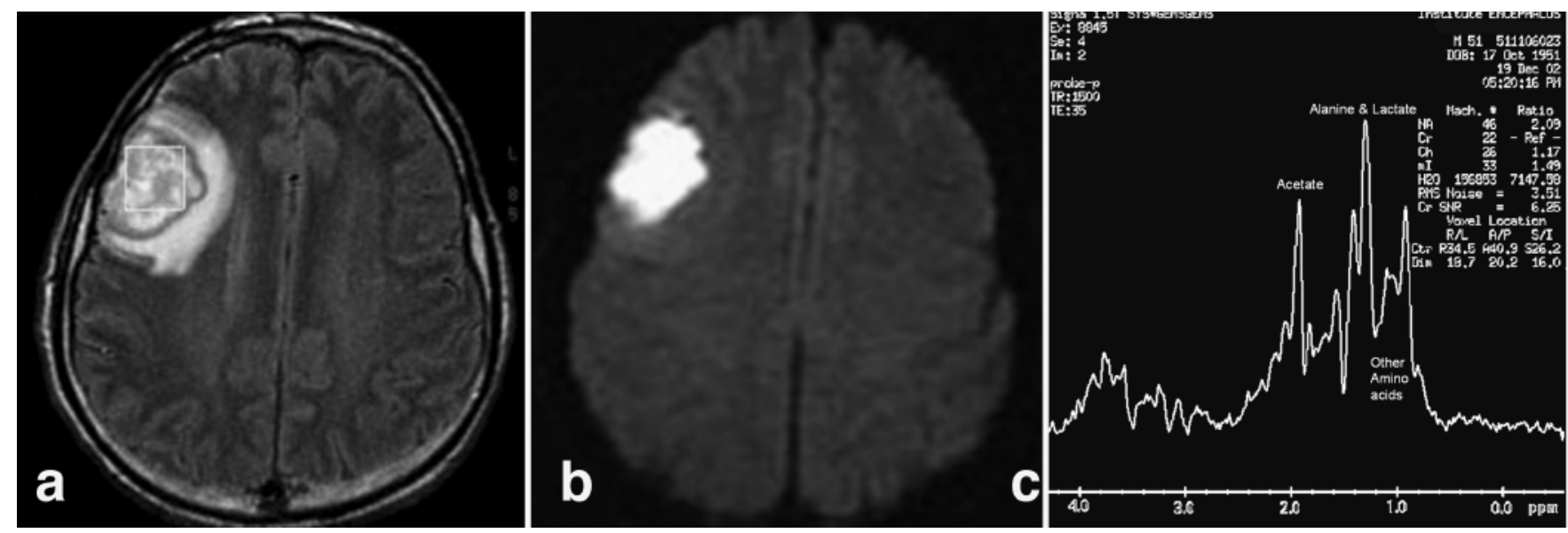

FIG. 3. a. T2-weighted MR image showing a right frontal lobe lesion surrounded by edema. b. Diffusion-weighted image demonstrating decreased diffusion of the lesion indicative of a brain abscess. c. Single voxel spectrum obtained in the same patient (1.5-t unit, Signa HS, GE).

\section{Diagnostic Accuracy}

Proton MR spectroscopy has been utilized quite successfully in the differential diagnosis of intracranial cystic/ necrotic lesions. ${ }^{8,17,23,26,30,38,39,42,44,52}$ The accuracy of this safe diagnostic tool has improved progressively since its introduction to the study of intracranial abscesses in $1994.7,20,29$ In a clinical prospective analysis conducted in 51 patients with intracranial cystic lesions that appeared similar on conventional MR imaging, Shukla-Dave et al. ${ }^{52}$ found that in vivo proton MR spectroscopy could accurate identify the underlying lesion in $92 \%$ of their cases. These results were confirmed on histopathological analysis and/or cultures obtained via an open craniotomy or stereotactic biopsy. Similarly in a large clinical study which included 98 patients with intracranial mass lesions, Poptani et al. ${ }^{44}$ reported $89 \%$ diagnostic accuracy with proton MR spectroscopy. In a prospective clinical study including 120 patients with intracranial lesions published by our group, we likewise reported a diagnostic accuracy of $85.6 \%$ with proton MR spectroscopy. ${ }^{11}$ Lai et al. ${ }^{31}$ evaluated the role of proton MR spectroscopy in the differential diagnosis of intracranial cystic mass lesions in a recent study and concluded that proton MR spectroscopy can significantly increase the diagnostic accuracy of conventional MR imaging. These authors found that the diagnostic accuracy, sensitivity, specificity, and the positive and negative predictive values of conventional MR images were 61.4, 61.9, 60.9, 59.1, and $63.3 \%$, respectively, while the respective rates for proton MR spectroscopy were 93.2, 85.1, 100, 100, and $88.5 \%$. Moreover, they reported that the addition of DW imaging increased the diagnostic accuracy further to $97.7 \%$, the sensitivity to $95.2 \%$, the specificity to $100 \%$, the positive predictive value to $100 \%$, and the negative predictive value to $95.8 \%$. Mishra et al. ${ }^{37}$ compared the DW imaging technique with proton MR spectroscopy analysis of ring-enhancing intracranial cystic mass lesions and found that the sensitivity of the former was 0.72 and its specificity 1 , while the values for the latter were 0.96 and 1. Moller-Hartmann et al..$^{38}$ reported that the addition of proton MR spectroscopy increased the diagnostic accuracy of conventional MR imaging by $15.4 \%$ in their series.

\section{Spectral Characteristics}

The spectral characteristics of intracranial abscesses can be summarized as follows: absence of NAA (detected at $2.0 \mathrm{ppm}$ ), absence of choline (detected at $3.2 \mathrm{ppm}$ ); absence of $\mathrm{PCr} / \mathrm{Cr}$ (detected at $3.0 \mathrm{ppm}$ ), presence of cytosolic amino acids such as leucine, isoleucine, and valine (detected at $0.9 \mathrm{ppm}$ ); presence of lactate (detected at 1.3 $\mathrm{ppm}$ ), acetate (detected at $1.92 \mathrm{ppm}$ ), succinate (detected at $2.4 \mathrm{ppm}$ ), and alanine (detected at $1.5 \mathrm{ppm}$ ); and occasionally lipids (mostly short-chain fatty acids such as butyric, isobutyric, caproic, propionic, valeric, and isovaleric acids,

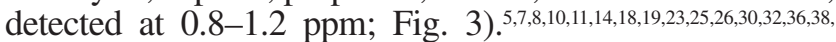
39,42,46,47,51,52,58

Cerebral abscesses contain no normal neurons. ${ }^{11,32}$ Therefore, no peaks of NAA or $\mathrm{PCr} / \mathrm{Cr}$ should be detected. The detection of any NAA or $\mathrm{PCr} / \mathrm{Cr}$ in a spectrum obtained from an abscess is indicative of either signal contamination or erroneous interpretation of an acetate peak as NAA. ${ }^{23}$ Similarly, no choline peak is present in an abscess's spectrum because there are no membranous structures in the necrotic lesional center. ${ }^{11,32}$ Cytosolic amino acids (leucine, isoleucine, and valine) are usually detected in cerebral abscesses. ${ }^{11,14,23,30,32,39,47,52,58}$ The detected amino acids are the products of proteolysis caused by enzymes released from neutrophil cells. ${ }^{23,32,47}$ Because these metabolites have never been detected in neoplasms, their detection is strongly indicative of a cerebral abscess. ${ }^{32}$ However, it must be emphasized that discriminating between lipids (usually detected at $0.8-1.2 \mathrm{ppm}$ ) and cytosolic amino acids (usually detected at $0.9 \mathrm{ppm}$ ) is of paramount importance because lipids may exist in both necrotic glial tumors and abscesses. ${ }^{30,32}$ The use of a TE of 135 and $\mathrm{J}$ coupling can help differentiate cytosolic amino acids from lipids. ${ }^{32}$ Cytosolic amino acids have also been detected in spectra obtained from neurocysticercosis lesions. ${ }^{1,57}$ Nevertheless, this finding is not confusing because the spectrum of cysticercosis is overall quite different, with characteristic concomitant increased concentrations of choline and $\mathrm{PCr} / \mathrm{Cr}{ }^{1}{ }^{1}$ In addition, Agarwal et al. ${ }^{1}$ have demonstrated that the presence of higher levels of succinate than acetate can differentiate cysticerci from anaerobic cerebral abscesses. ${ }^{35}$ Increased con- 
centrations of lactate are found in abscess spectra. ${ }^{11,16,32}$ It is well known that bacterial fermentation of glucose-via the Embden-Meyerhof metabolic pathway-produces a large pool of pyruvate, which is then converted to lactate. ${ }^{46}$ Acetate may be produced during heterolactic fermentation, propionic acid fermentation, or mixed acid fermentation..$^{32}$ The detection of acetate depends on the presence of acetyl-coenzyme A. Therefore, detection of acetate in variable concentrations suggests an abscess of bacterial origin. ${ }^{32,46}$ In addition, succinate is a product of propionic acid fermentation and mixed acid fermentation in various anaerobic bacteria. $^{32,47}$ The presence of succinate has therefore been seen by most investigators as evidence of anaerobic bacterial activity. ${ }^{23,32,46,58}$ The presence of acetate and succinate peaks has been associated with pyogenic brain abscesses, especially those involving obligate anaerobes or a mixture of obligate and facultative anaerobes. ${ }^{13,23,32,46}$ On the other hand, the absence of acetate and succinate has been associated with abscesses caused by aerobes and facultative anaerobes. ${ }^{13,32}$ These findings can be explained by the fact that the pyruvate produced from glycolysis follows the tricarboxylic acid cycle. ${ }^{13,32}$ Alanine may be occasionally detected in abscess spectra; however, the specificity of this marker is limited because is it also detected in increased concentrations in meningiomas. ${ }^{42}$

Spectra obtained in abscesses should be differentiated from other lesions with similar conventional MR imaging characteristics. To differentiate abscesses from high-grade gliomas (anaplastic astrosytoma or glioblastoma multiforme), the detection of $\mathrm{PCr} / \mathrm{Cr}$ in the later is of paramount importance. ${ }^{12,16,23,27,30,33,42,43,52}$ This metabolite is always detectable in gliomas but is not detected in abscesses. ${ }^{12,16}$, 23,27,30,33,42,43,52 Similarly, the absence of choline can further help in establishing the diagnosis of an abscess, because choline production is increased in high-grade tumors due to increased membranous structures in these tumors.11,12 Lipids may be detected in both lesions. $12,15,16,23,27,30,33,42,43,52$ Similarly, lactate (a product of anaerobic glycolysis) can be found both in brain abscesses and in high-grade glial tumors, and its presence cannot serve as a pathognomonic spectroscopic marker. ${ }^{11}$

Likewise, increased concentration of choline can be helpful in differentiating between abscesses and lymphomas because this metabolite is always increased in lymphomas and absent in abscesses. ${ }^{9}$ The detection of lipids cannot help in differentiating between them. ${ }^{9}, 15$ Chang et al. ${ }^{8}$ have reported that spectroscopic analysis of lymphomas in patients with AIDS demonstrated markedly increased concentrations of choline, and mildly to moderately elevated concentrations of lactate and lipids.

\section{Identification of Causative Agent}

The role of proton MR spectroscopy is not limited to providing a prompt diagnosis of abscess. This modality can also offer valuable information useful in the identification of the causative organism. Lai et al. ${ }^{32}$ described 3 spectroscopic patterns of pyogenic cerebral abscesses. Pattern A, characterized by the presence of lactate, cytosolic amino acids, alanine, acetate, succinate, and lipids, is mostly associated with obligate anaerobes or a mixture of obligate and facultative anaerobes. Spectroscopic Pattern B, characterized by the presence of lactate, cytosolic amino acids, and the occasional presence of lipids, is mostly associated with obligate aerobes and facultative anaerobes. Finally, Pattern $\mathrm{C}$ is characterized by the presence of lactate and is associated with Streptococcus spp. Himmelreich and colleagues ${ }^{22}$ have reported that abscesses due to Staphylococcus infection had characteristic peaks from lipids and lactate. This finding has apparent clinical impact on the early selection of the appropriate antibiotic treatment in patients with abscesses.

The reported spectral characteristics of tubercular cerebral abscesses can be summarized as increased concentrations of lipids and phosphoserine. .,34,43 $^{73}$ The spectral characteristics of fungal abscesses remain undefined. Luthra et al. ${ }^{34}$ reported that cytosolic amino acids and lactate were detected in the majority of the fungal abscesses they treated, while lipids and lactate or lactate alone were found less consistently in their series. Interestingly, a peak at 3.6 and $3.8 \mathrm{ppm}$ representing trehalose was observed in the majority of their fungal abscesses (a component of the fungal wall). Soto-Hernández and colleagues ${ }^{55}$ reported on the spectral characteristics of Nocardia abscesses and found that cytosolic amino acids and lactate were the only detected metabolites (Table 1). Before closing the discussion regarding the spectral signature of an abscess, we must emphasize that the obtained spectrum can be influenced not only by the bacterial strain itself but also by the regional tissue oxygen and $\mathrm{CO}_{2}$ partial pressures, as well as the regional tissue glucose concentration. ${ }^{23}$

\section{Evaluation of Abscess Evolution}

Interestingly, the observations of temporal spectral changes published by Akutsu and associates ${ }^{2}$ can be used to obtain valuable information regarding the response of a studied abscess to the surgical or medical treatment applied. These authors used sequential spectroscopic analysis of brain abscesses to detect changes in the concentrations of metabolites. Characteristically, they found an absence of acetate, succinate, and cytosolic amino acids after the surgical evacuation, while all of these metabolites were present preoperatively. It is apparent that as the histological structure of an evolving cerebral abscess changes, these changes induce biochemical changes that may be noticeable on the obtained MR spectrum. Spectroscopic analysis can also provide information regarding the exact histological stage of the studied abscess (early compared with late cerebritis and early compared with late capsular forma-

TABLE 1

Spectral characteristics of various types of abscesses*

\begin{tabular}{|c|c|}
\hline Type of Abscess & ${ }^{1} \mathrm{HMRS}$ Profile \\
\hline pyogenic anaerobic & $\begin{array}{l}\text { cytosolic amino acids, lipids, alanine, } \\
\text { acetate, succinate, \& lactate }\end{array}$ \\
\hline pyogenic aerobic & lactate, cytosolic amino acids, \& lipids \\
\hline pyogenic streptococcal & lactate \\
\hline pyogenic staphylococcal & lipids \& lactate \\
\hline tubercular & lipids \& phosphoserine \\
\hline fungal & lipids \& lactate \\
\hline Nocardia & cytosolic amino acids \& lactate \\
\hline cysticercus & $\begin{array}{l}\text { cytosolic amino acids, lactate, alanine, } \\
\text { acetate, succinate, \& choline }\end{array}$ \\
\hline
\end{tabular}

* Abbreviation: ${ }^{1} \mathrm{HMRS}=$ proton MR spectroscopy. 
tion), ${ }^{3,4}$ The noninvasive evaluation of the histological stage of a cerebral abscess may have significant clinical impact as this kind of information can influence the selection of the most appropriate (medical or surgical) therapy and thus favorably alter the overall clinical outcome in these patients.

\section{Conclusions}

In our present study, we have shown that proton MR spectroscopy is a safe and noninvasive imaging modality, which, under technically advanced settings, can accurately differentiate between necrotic/cystic tumors and cerebral abscesses. The use of this modality in combination with DW imaging can significantly increase the diagnostic accuracy of conventional MR imaging and provide valuable preoperative information regarding the nature of spaceoccupying, ring-enhancing intracranial lesions. Moreover, proton MR spectroscopy can also provide clues to the cause of an abscess, and consequently, its likely response to medical or surgical treatment. However, the promising role of proton MR spectroscopy in delineating the specific causes of intracranial abscesses requires further clinical investigation and validation of the existing results.

\section{References}

1. Agarwal M, Chawla S, Husain N, Jaggi RS, Husain M, Gupta RK: Higher succinate than acetate levels differentiate cerebral degenerating cysticerci from anaerobic abscesses on in-vivo proton MR spectroscopy. Neuroradiology 46:211-215, 2004

2. Akutsu H, Matsumura A, Isobe T, Anno I, Takano S, Itai Y, et al: Chronological change of brain abscess in ${ }^{1} \mathrm{H}$ magnetic resonance spectroscopy. Neuroradiology 44:574-578, 2002

3. Britt RH, Enzmann DR: Clinical stages of human brain abscesses on serial CT scans after contrast infusion. Computerized tomographic, neuropathological, and clinical correlations. J Neurosurg 59:972-989, 1983

4. Britt RH, Enzmann DR, Yeager AS: Neuropathological and computerized tomographic findings in experimental brain abscess. $\mathbf{J}$ Neurosurg 55:590-603, 1981

5. Burtscher IM, Holtås S: In vivo proton MR spectroscopy of untreated and treated brain abscesses. AJNR Am J Neuroradiol 20:1049-1053, 1999

6. Castillo M, Kwock L, Mukherji SK: Clinical applications of proton MR spectroscopy. AJNR Am J Neuroradiol 17:1-15, 1996

7. Cecil KM, Lenkinski RE: Proton MR spectroscopy in inflammatory and infectious brain disorders. Neuroimaging Clin N Am 8: 863-880, 1998

8. Chang KH, Song IC, Kim SH, Han MH, Kim HD, Seong SO, et al: In vivo single-voxel proton MR spectroscopy in intracranial cystic masses. AJNR Am J Neuroradiol 19:401-405, 1998

9. Chinn RJ, Wilkinson ID, Hall-Craggs MA, Paley MN, Miller RF, Kendall BE, et al: Toxoplasmosis and primary central nervous system lymphoma in HIV infection: diagnosis with MR spectroscopy. Radiology 197:649-654, 1995

10. Dev R, Gupta RK, Poptani H, Roy R, Sharma S, Husain M: Role of in vivo proton magnetic resonance spectroscopy in the diagnosis and management of brain abscesses. Neurosurgery 42:37-43, 1998

11. Fountas KN, Kapsalaki EZ, Gotsis SD, Kapsalakis JZ, Smisson HF III, Johnston KW, et al: In vivo proton magnetic resonance spectroscopy of brain tumors. Stereotact Funct Neurosurg 74: 83-94, 2000

12. Fountas KN, Kapsalaki EZ, Vogel RL, Fezoulidis I, Robinson JS, Gotsis ED: Noninvasive histological grading of solid astrocy- tomas using proton magnetic resonance spectroscopy. Stereotact Funct Neurosurg 82:90-97, 2004

13. Garg M, Gupta RK, Husain M, Chawla S, Chawla J, Kumar R, et al: Brain abscesses: etiologic categorization with in vivo proton MR spectroscopy. Radiology 230:519-527, 2004

14. Garg M, Misra MK, Chawla S, Prasad KN, Roy R, Gupta RK: Broad identification of bacterial type from pus by $1 \mathrm{H}$ MR spectroscopy. Eur J Clin Invest 33:518-524, 2003

15. Gotsis E, Fountas K, Kapsalaki E, Toulas P, Peristeris G, Papadakis N: In vivo proton MR spectroscopy: the diagnostic possibilities of lipid resonances in brain tumors. Anticancer Res 16: 1565-1567, 1996

16. Grand S, Laï ES, Estève F, Rubin C, Hoffmann D, Rémy C, et al: In vivo $1 \mathrm{H}$ MRS of brain abscesses versus necrotic brain tumors. Neurology 47:846-848, 1996

17. Grand S, Passaro G, Ziegler A, Estève F, Boujet C, Hoffmann D, et al: Necrotic tumor versus brain abscess: importance of amino acids detected at ${ }^{1} \mathrm{H}$ MR spectroscopy—initial results. Radiology 213:785-793, 1999

18. Gupta RK, Vatsal DK, Husain N, Chawla S, Prasad KN, Roy R, et al: Differentiation of tuberculous from pyogenic brain abscesses with in vivo proton MR spectroscopy and magnetization transfer MR imaging. AJNR Am J Neuroradiol 22: 1503-1509, 2001

19. Haimes AB, Zimmerman RD, Morgello S, Weingarten K, Becker RD, Jennis R, et al: MR imaging of brain abscesses. AJR Am J Roengenol 152:1073-1085, 1989

20. Harada M, Tanouchi M, Miyoshi H, Nishitani H, Kannuki S: Brain abscess observed by localized proton magnetic resonance spectroscopy. Magn Reson Imaging 12:1269-1274, 1994

21. Henson JW, Ferraro MJ: Case records of the Massachusetts General Hospital. Weekly clinicopathological exercises. Case 43-1993. A 71-year-old woman with confusion, hemianopia, and an occipital mass. N Engl J Med 329:1335-1341, 1994

22. Himmelreich U, Accurso R, Malik R, Dolenko B, Somorjai RL, Gupta RK, et al: Identification of Staphylococcus aureus brain abscesses: rat and human studies with $1 \mathrm{H}$ MR spectroscopy. Radiology 236:261-270, 2005

23. Kadota O, Kohno K, Ohue S, Kumon Y, Sakaki S, Kikuchi K, et al: Discrimination of brain abscess and cystic tumor by in vivo proton magnetic resonance spectroscopy. Neuro Med Chir (Tokyo) 41:121-126, 2001

24. Kamada K, Houkin K, Abe H, Sawamura Y, Kashiwaba T: Differentiation of cerebral radiation necrosis from tumor recurrence by proton magnetic resonance spectroscopy. Neurol Med Chir (Tokyo) 37:250-256, 1997

25. Kaminogo M, Ishimaru H, Morikawa M, Suzuki Y, Shibata S: Proton MR spectroscopy and diffusion-weighted MR imaging for the diagnosis of intracranial tuberculomas. Report of two cases. Neurol Res 24:537-543, 2002

26. Kim SH, Chang KH, Song IC, Han MH, Kim HC, Kang HS, et al: Brain abscess and brain tumor: discrimination with in vivo $\mathrm{H}-1$ MR spectroscopy. Radiology 204:239-245, 1997

27. Kimura T, Sako K, Gotoh T, Tanaka K, Tanaka T: In vivo singlevoxel proton MR spectroscopy in brain lesions with ring-like enhancement. NMR Biomed 14:339-349, 2001

28. Klug N, Ellams ID: Difficulties in the differential diagnosis of brain abscesses. Adv Neurosurg 9:61-67, 1981

29. Kohli A, Gupta RK, Poptani H, Roy R: In vivo proton magnetic resonance spectroscopy in a case of intracranial hydatid cyst. Neurology 45:562-564, 1995

30. Lai PH, Ho JT, Chen WL, Hsu SS, Wang JS, Pan HB, et al: Brain abscess and necrotic brain tumor: discrimination with proton $\mathrm{MR}$ spectroscopy and diffusion-weighted imaging. AJNR Am J Neuroradiol 23:1369-1377, 2002

31. Lai PH, Hsu SS, Ding SW, Ko CW, Fu JH, Weng MJ, et al: Proton magnetic resonance spectroscopy and diffusion-weighted imaging in intracranial cystic mass lesions. Surg Neurol 68 (1 Suppl):25-36, 2007 
32. Lai PH, Li KT, Hsu SS, Hsiao CC, Yip CW, Ding S, et al: Pyogenic brain abscess: findings from in vivo 1.5 -t and 11.7 -t in vitro proton MR spectroscopy. AJNR Am J Neuroradiol 26:279288, 2005

33. Lau DW, Klein NC, Cunha BA: Brain abscess mimicking brain tumor. Heart Lung 18:634-637, 1989

34. Luthra G, Parihar A, Nath K, Jaiswal S, Prasad KN, Husain N, et al: Comparative evaluation of fungal, tubercular, and pyogenic abscesses with conventional and diffusion MR imaging and proton MR spectroscopy. AJNR Am J Neuroradiol 28:1332-1338, 2007

35. Mamelak AN, Mampalam TJ, Obana WG, Rosenblum ML: Improved management of multiple brain abscesses: a combined surgical and medical approach. Neurosurgery 36:76-86, 1995

36. Martinez-Pérez I, Moreno A, Alonso J, Aguas J, Conesa G, Capdevila A, et al: Diagnosis of brain abscess by magnetic resonance spectroscopy. Report of two cases. J Neurosurg 86:708-713, 1997

37. Mishra AM, Gupta RK, Jaggi RS, Reddy JS, Jha DK, Husain N, et al: Role of diffusion-weighted imaging and in vivo proton magnetic resonance spectroscopy in the differential diagnosis of ringenhancing intracranial cystic mass lesions. J Comput Assist Tomogr 28:540-547, 2004

38. Möller-Hartmann W, Herminghaus S, Krings T, Marquardt G, Lanfermann H, Pilatus U, et al: Clinical application of proton magnetic resonance spectroscopy in the diagnosis of intracranial mass lesions. Neuroradiology 44:371-381, 2002

39. Nakaiso M, Uno M, Harada M, Kageji T, Takimoto O, Nagahiro $\mathrm{S}$ : Brain abscess and glioblastoma identified by combined proton magnetic resonance spectroscopy and diffusion-weighted magnetic resonance imaging-two case reports. Neurol Med Chir (Tokyo) 42:346-348, 2002

40. Negendank W: Studies of human tumors by MRS: a review. NMR Biomed 5:303-324, 1992

41. Negendank WG, Sauter R, Brown TR, Evelhoch JL, Falini A, Gotsis ED, et al: Proton magnetic resonance spectroscopy in patients with glial tumors: a multicenter study. J Neurosurg 84: 449-458, 1996

42. Poptani H, Gupta RK, Jain VK, Roy R, Pandey R: Cystic intracranial mass lesions: possible role of in vivo MR spectroscopy in its differential diagnosis. Magn Reson Imaging 13:10191029, 1995

43. Poptani H, Gupta RK, Roy R, Pandey R, Jain VK, Chhabra DK: Characterization of intracranial mass lesions with in vivo proton MR spectroscopy. AJNR Am J Neuroradiol 16:1593-1603, 1995

44. Poptani H, Kaartinen J, Gupta R, Niemitz M, Hiltunen Y, Kauppinen RA: Diagnostic assesment of brain tumours and non-neoplastic disorders in vivo using nuclear magnetic resonance spectroscopy and artificial neuronal networks. J Cancer Res Clin Oncol 125:343-349, 1999

45. Preul MC, Caramanos Z, Collins DL, Villemure JG, Leblanc R, Olivier A, et al: Accurate, noninvasive diagnosis of human brain tumors by using proton magnetic resonance spectroscopy. Nat Med 2:323-325, 1996
46. Rand SD, Prost R, Li SJ: Proton MR spectroscopy of the brain. Neuroimaging Clin N Am 9:379-395, 1999

47. Remy M, Grand S, Lai ES, Belle V, Hoffmann D, Berger F, et al: 1HRMS of human brain abscesses in vivo and in vitro. Magn Reson Med 34:508-514, 1995

48. Ross B, Michaelis T: Clinical applications of magnetic resonance spectroscopy. Magn Reson Q 10:191, 1994

49. Sabatier J, Tremoulet M, Ranjeva JP, Manelfe C, Berry I, Gilard $\mathrm{V}$, et al: Contribution of in vivo $1 \mathrm{H}$ spectroscopy to the diagnosis of deep-seated brain abscess. J Neurol Neurosurg Psychiatry 66: $120-121,1999$

50. Sartor K: MR Imaging of the Skull and Brain: A Correlative Text Atlas. Heidelberg: Springer-Verlag, 1992, pp 74-95

51. Schumacher DJ, Nelson TR, van Sonnenberg E, Meng TC, Hlavin P: AUR Memorial Award 1992. Quantification of amino acids in human body fluids by $1 \mathrm{H}$ magnetic resonance spectroscopy. A specific test for the identification of abscess. Invest Radiol 27:999-1004, 1992

52. Shukla-Dave A, Gupta RK, Roy R, Husain N, Paul L, Venkatesh SK, et al: Prospective evaluation of in vivo proton MR spectroscopy in differentiation of similar appearing intracranial cystic lesions. Magn Reson Imaging 19:103-110, 2001

53. Sijens PE, Knopp MV, Brunetti A, Wicklow K, Alfano B, Bachert P, et al: $1 \mathrm{H}$ MR spectroscopy in patients with metastatic brain tumors: a multicenter study. Magn Reson Med 33:818-826, 1995

54. Sijens PE, van den Bent MJ, Nowak PJ, van Dijk P, Oudkerk M: $1 \mathrm{H}$ chemical shift imaging reveals loss of brain tumor choline signal after administration of Gd-contrast. Magn Reson Med 37:222-225, 1997

55. Soto-Hernández JL, Moreno-Andrade T, Góngora-Rivera F, Ramirez-Crescencio MA: Nocardia abscess during treatment of brain toxoplasmosis in a patient with aids, utility of proton MR spectroscopy and diffusion-weighted imaging in diagnosis. Clin Neurol Neurosurg 108:493-498, 2006

56. Taylor JS, Langston JW, Reddick WE, Kingsley PB, Ogg RJ, Pui $\mathrm{MH}$, et al: Clinical value of proton magnetic resonance spectroscopy for differentiating recurrent or residual brain tumor from delayed cerebral necrosis. Int J Radiat Oncol Biol Phys 36: 1251-1261, 1996

57. Tripathi RP, Gupta A, Gupta S, Kumaran SS, Khushu S, Dev A, et al: Co-existence of dual intracranial pathology clinical relevance of proton MRS. Neurol India 48:365-369, 2000

58. Tsui EYK, Chan JH, Cheung YK, Lai KF, Fong D, Ng SH: Evaluation of cerebral abscesses by diffusion-weighted MR imaging and MR spectroscopy. Comput Med Imaging Graph 26: 347-351, 2002

Manuscript submitted February 15, 2008.

Accepted March 12, 2008.

Address correspondence to: Kostas N. Fountas, M.D., Ph.D., Labrou Katsoni Street, Terpsithea 41500, Larissa, Greece. email: fountas@med.uth.gr. 